\title{
Stability of young children's attachment representations: Influence of children's and caregiver's characteristics ${ }^{2}$
}

\author{
M. Stievenart*, I. Roskam, J.-C. Meunier, G. Van de Moortele \\ Université Catholique de Louvain, Institute of Research in Psychological Sciences, Place Cardinal Mercier, 10, 1348 Louvain-la-Neuve, Belgium
}

\section{A R T I C L E I N F O}

\section{Article history:}

Received 13 April 2012

Received in revised form 2 December 2013

Accepted 10 December 2013

Available online 13 January 2014

\section{Keywords:}

Attachment representations

Developmental trajectories

Parenting

IQ

Externalizing behaviors

\begin{abstract}
A B S T R A C T
This research explores the stability of attachment representations, assessed by the Attachment Story Completion Task, within early childhood. Hypotheses were also formed about the influence of parenting, externalizing behavior and intelligence quotient (IQ) on the developmental course of children's attachment representations. Data were collected from 358 French-speaking Belgian children. Security and disorganization showed a linear improvement with age. The effect of time on the two growth curves was influenced by the child's externalizing behavior. When language abilities were controlled for in a subsample of referred children for externalizing behavior, the growth in security was found to be influenced by reasoning IQ but the effects for disorganization were unchanged. The implications of the results for both research and clinical purposes are discussed.
\end{abstract}

(c) 2013 Elsevier Inc. All rights reserved.
The stability of attachment representations has been studied for a long time. Most results indicate that the individual's attachment pattern remains stable over the course of his/her development. However, only a few studies have been devoted to the stability of attachment within childhood. The present study focuses on the stability of children's attachment representations from three to eight years of age, using the French version of the Attachment Story Completion Task (Fr-ASCT; Bretherton, Ridgeway, \& Cassidy, 1990) in the context of a three-wave longitudinal study that allows an accelerated design to be used with three cohorts of children : one of three-year-old children ( $n=87$ ), one of four-year-old children ( $n=103)$ and one of five-year-old children $(n=105)$.

\section{Empirical and conceptual studies of attachment stability}

The stability of attachment has been empirically considered either within or across several developmental time periods, based on either attachment behaviors or attachment representations. Only studies dealing with stability in infancy and childhood are relevant for our purposes, so only these are reviewed below.

Studies involving both infants and preschool children have mainly focused on attachment behavior because the rudimentary verbal skills of these children make the measurement of attachment representations difficult. Numerous studies of infants have analyzed the stability of attachment behaviors with the Strange Situation Procedure (SSP; Ainsworth, Blehar, Waters, \& Wall, 1978). In this context, children

\footnotetext{
is This work was supported by the Fonds Marguerite-Marie Delacroix.

* Corresponding author.

E-mail address: marie.stievenart@uclouvain.be (M. Stievenart).
}

were shown to differ in their balance between exploration and attachment behaviors in distressing situations. Avoidant children tended to minimize their attachment behaviors in favor of their exploration behaviors, whereas ambivalent children tended to maximize their attachment behaviors to the detriment of their exploration behaviors. Secure children achieved an optimal balance between attachment and exploratory behaviors. Authors have reported a wide range of values for the stability of these patterns, with kappas ranging from .14 to .92 (e.g. Bar-Haim, Sutton, \& Fox, 2000; Egeland \& Farber, 1984; van Ijzendoorn, Vereijken, Bakermans-Kranenburg, \& Riksen-Walraven, 2004). Studies investigating the permanence of attachment behaviors in childhood are less numerous and have concluded that attachment security is moderately stable in childhood (Moss, Cyr, Bureau, Tarabulsy, \& Dubois-Comtois, 2005; Symons, Clark, Isaksen, \& Marshall, 1998). The available results were obtained with either the SSP or the Attachment Q-set (AQS, Waters \& Deane, 1985), consisting of a large number of cards describing the child's behavior in the natural home setting. For instance, items characterizing a secure child include "the child is friendly with strangers" and "the child is independent of his/her mother; he/ she can play on his/her own".

While children's attachment behavior has been related to attachment representations (e.g. Bretherton et al., 1990; Gloger-Tippelt, Gomille, Koenig, \& Vetter, 2002; Solomon, George, \& De Jong, 1995), to date, and to the best of our knowledge, only one study has explored the stability of attachment representations among young children (Green, Stanley, Smith, \& Goldwyn, 2000). The authors reported a $76.5 \%$ short-term correspondence (with a six-month interval) across the three traditional attachment patterns using the Manchester Child Attachment Story Task. The major aim of the current study is to replicate 
this result over a longer term using an instrument especially designed for young children's attachment representations: the Attachment Story Completion Task (ASCT; Bretherton et al., 1990).

Moreover, most of the studies reviewed above were concerned with the stability of security/insecurity, but they only rarely considered the stability of disorganization (Moss et al., 2005; Weinfield, Whaley, \& Egeland, 2004). Disorganized children seem to be unable to cope with stress in difficult situations and lack a clear and coherent strategy for using the caregiver as a source of comfort. Main and Hesse (1990) suggest that, in such cases, the parent is seen as both a source of comfort and a source of fear. Disorganized children are then faced with a dilemma: whether to approach or to withdraw from their parent (Green \& Goldwyn, 2002). Such a dilemma is considered as an obstacle to the development of organized strategies or as a breakdown of an existing strategy, whether secure or insecure. One meta-analysis (van Ijzendoorn, Schuengel, \& Bakermans-Kranenburg, 1999) recorded moderate stability of short and long term disorganization in infants $(r=.34)$. This result was recently confirmed by Moss et al. (2005) who found a $77 \%$ correspondence between preschoolers' disorganized attachment patterns over time. These results suggest that attachment disorganization, like security, is relatively stable across the infancy and preschool developmental periods. Because disorganization has been found to be an even greater risk factor for developmental disorders than insecurity (e.g. Green \& Goldwyn, 2002; Weinfield et al., 2004), we decided to explore the stability of both attachment security and disorganization in this study.

\section{Children's and caregiver's characteristics as influencing attachment stability}

Some children's and caregiver's characteristics could influence the attachment stability but have rarely been investigated. However, attachment stability has been reported to be affected both by the caregiving environment and by the child's characteristics (Weinfield et al., 2004). Bowlby (in Weinfield et al., 2004, p. 74) originally suggested that attachment representations become increasingly resistant to change when the caregiving environment remains stable and reinforces them. On the other hand, he considered attachment representations to be dynamic and susceptible to change if there were substantial variations in the caregiving environment.

One of the major determinants in the caregiving environment is parenting. Parents facilitate their children's positive internal representations of themselves as lovable, and positive views of the parent as available, through support, responsiveness and the promotion of children's individuality (De Wolff \& van Ijzendoorn, 1997; Karavasilis, Doyle, \& Markiewicz, 2003). There are several limitations in the available literature on attachment and parenting, and these were taken into account in the present study. First, only a few of the existing attachment stability studies tested the effect of parenting on the developmental course of attachment. Parenting was related to changes in attachment behaviors in infancy (Egeland \& Farber, 1984) as well as in toddlerhood (Huang, O'Brien Caughy, Lee, Miller, \& Genevro, 2009). However Weinfield et al. (2004) could not replicate these results across two developmental periods from infancy to adulthood. Second, most studies dealing with the relations between parenting and attachment only considered mothers. None of them took fathers into account. Third, most of the previous studies examining this relation considered parenting to be simple and permanent, and so used a single measure to characterize parenting once and for all. Very few previous studies have empirically recognized parenting as a dynamic variable as children grow older, demanding a longitudinal approach (Huang et al., 2009; Roskam \& Meunier, 2012). These authors recognize that there is no absolute stability in parenting. The current study therefore considered the combined effect of mothers' and fathers' parenting on attachment stability as a dynamic effect during the two-year follow-up, and as having an influence on the developmental course of attachment stability.
In addition to factors within the caregiving environment, children's own characteristics may also influence the developmental course of attachment. Except for the influence of temperament (e.g. Egeland \& Farber, 1984; Weinfield et al., 2004), very few studies have considered the moderating effect of an individual's characteristics. This is somewhat surprising because current attachment representations are cognitive concepts, and their level of elaboration might well depend on children's cognitive capacities. In this context, intelligence quotient (IQ) could be a resilient factor in the development of attachment representations, as measured by ASCT for instance. Based on previous work indicating reciprocal relations between preschoolers' IQ and attachment representations (Stievenart, Meunier, Van de Moortele, \& Roskam, 2012; Stievenart, Roskam, Meunier, \& Van de Moortele, 2011), both reasoning and verbal IQ are hypothesized to have an influence on the developmental course of attachment. Children with higher IQ are expected to be more likely to maintain their secure and organized previous attachment representations in the face of modifications in parenting because they have the ability to cope with new relational and social information (Crittenden, 1990). Conversely, modifications in parenting would be more likely to disturb the attachment representations of children with lower IQ because of their inability to integrate new social and relational information without a radical transformation of their attachment representations (Crittenden, 1990).

In addition, a moderating effect of gender was tested. Several authors have reported that when children's attachment representations were assessed with the ASCT, boys were more disorganized (Miljkovitch \& Pierrehumbert, 2008; Miljkovitch, Pierrehumbert, Bretherton, \& Halfon, 2004; Miljkovitch, Pierrehumbert, Karmaniola, \& Halfon, 2003; Pierrehumbert et al., 2009) and less secure than girls (Green, Stanley, \& Peters, 2007; Pierrehumbert et al., 2009). Due to these differences between boys and girls, the moderating effect of gender on attachment stability was explored here.

Finally, externalizing behavior (EB), characterized by agitation, opposition, aggression, provocation and transgression of social norms, is often related to attachment behaviors. Most previous studies have concluded that insecure patterns are related to later EB in children (e.g. Fearon, Bakermans-Kranenburg, van Ijzendoorn, Lapsley, \& Roisman, 2010; Moss et al., 2006; Pierrehumbert, Miljkovitch, Plancherel, Halfon, \& Ansermet, 2000), although some research has concluded that disorganization is a major risk factor for development disorders, especially EB - perhaps even a greater risk than insecurity (for a metaanalysis, see van Ijzendoorn et al., 1999). Studies considering the relations between attachment representations (rather than attachment behaviors) and EB are far less numerous. Those that do exist reach similar conclusions: both insecure (Gloger-Tippelt, Lilith, \& Olaf, 2008; Stacks, 2007) and disorganized children (Gloger-Tippelt et al., 2008; Ongari, 2008) display a higher level of EB than secure children. These results, obtained with reference to both attachment behavior and attachment representations, indicate the importance of considering EB in relation to attachment stability, because the level of EB could have an impact on the attachment stability.

\section{Language ability and attachment stability}

Language abilities, rather than age, may influence attachment stability, although previous researchers (Bretherton, 2008; Gloger-Tippelt et al., 2008; Miljkovitch, Pierrehumbert, \& Halfon, 2007) have suggested that language abilities do not play any role in story completion because the use of material allows the child to depict his/her representations without speaking. In our experience, however, it was difficult to carry out the coding procedure on the narratives when the child did not speak or spoke very little, resulting in false estimates of the attachment patterns. Thus language abilities could also play a significant role in the completion of the Fr-ASCT stories and hence influence the apparent nature of children's attachment representations. The effect of language abilities was therefore controlled for in a subsample of children for 
whom such data were available (details about this sample here under). These analyses allowed us to interpret the effects of children's and caregiver's characteristics on the stability of attachment, over and above the child's language abilities.

\section{Current research}

The present study focuses on the stability of attachment representations, assessed with the Fr-ASCT, in young childhood and broadens the scope of previous research in four important ways. First, the design of our study is quite specific. Children's attachment representations were assessed in a three-wave longitudinal design whereas most previous studies have only assessed children's attachment behavior twice. This longitudinal design allows us to consider our data as derived from an accelerated design using three cohorts of children aged three years old, four years old and five years old respectively.

Second, in the current literature, most studies employed categorical scores when analyzing stability, and found moderate to high stability (e.g. Gloger-Tippelt et al., 2002; Moss et al., 2005). Studies using continuous scores are rare, although such scores allow variations among individuals classified into the same pattern to be taken into account, for instance by illustrating the relative level of security/insecurity (Cummings, 2003). This could be useful for our research purposes (Cassidy, 2003; Cummings, 2003; Cummings, Greenberg, \& Cicchetti, 1990 ) because it is possible that continuous scores, by providing a more nuanced picture of children's attachment profiles, might reveal different aspects of their stability.

Third, another innovation in our study is the analysis of the stability of attachment security as well as attachment disorganization. In line with previous studies, moderate to high stability of attachment representations in childhood was hypothesized, for both security and disorganization.

Fourth, the impact of children's and caregiver's characteristics influencing on attachment stability has not often been examined in previous studies. In our study, we considered various hypotheses about the moderating effects of parenting, IQ EB and gender on the developmental course of attachment. An increase in supportive parenting during the two-year follow-up was expected to be linked to an increase in children's security and/or a decrease in children's disorganization over time. Among the children's characteristics, higher IQ and lower EB were hypothesized to maintain the stability or to increase security or disorganization in attachment over the two-year period. The effect of gender was also explored. Boys were expected to be more disorganized and less secure. Also, the effect of language abilities was controlled for in a subsample of children. These analyses allowed us to interpret the effects of children's and caregiver's characteristics on the stability of attachment, over and above the child's language abilities.

\section{Method}

\section{Sample and procedure}

This study was part of the longitudinal 'H2M (Hard-to-Manage) Children' research program, which is being conducted by the Psychological
Sciences Research Institute at the Universite catholique de Louvain, Belgium (UCL), in collaboration with Cliniques universitaires Saint-Luc in Brussels. Data were collected from a group of 358 French-speaking Belgian children (57.5\% boys), some of whom had been referred to specialists for their behavior problems and others of whom were developing normally. The non-referred cohort $(n=245)$ were recruited when the children were 30 to 91 months old and enrolled in the first to third years of kindergarten in various primary schools in the Frenchspeaking part of Belgium. Note that kindergarten schooling (also known as pre-school education) in Belgium lasts three years, from three to six years of age. The referred group $(n=113)$ was recruited from pediatric units in Belgian hospitals where they had been referred for EB. The referral had to have been made by a doctor after a diagnosis of EB, which was the immediate and principal reason for the referral. Children displaying substantial language delays or developmental disorders were excluded from the sample. At the time they were recruited, all the children were attending normal schools.

EB was considered as a continuum ranging from normal to pathological levels. A certain overlap was therefore seen between the two subsamples, because several non-referred children displayed a moderate to high level of EB and several referred children displayed only a moderate level. Also, because the socio-demographic characteristics of the two subsamples were very similar (see Table 1 ) with the exception of gender composition (girls being under-represented in the referred sample), they could be taken together to form a single sample.

Consequently, by considering both referred and non-referred children, we maximized the range on the continuum from normal to pathological behavior in children. Note that the way referrals for EB in Belgium are treated means that very young children can be referred for behavioral problems to a pediatrician or to mental health services, but in the absence of a neurological or biological origin of the problem, neither diagnosis nor systematic treatment is provided under the age of seven. In this context, the referred children in our sample had not undergone any systematic treatments including medication between the three waves of assessment, although a few of them (9\%) had taken part in psychomotor activities conducted by physiotherapists. The frequency of such activities, their relation to EB and its correlates were controlled for and found not to have any significant effect on the variables under consideration.

The parents were informed about the study and asked if they would be willing to participate in a longitudinal research program. They were assured that the data would remain confidential. Informed consent was obtained from all the adult participants.

The data presented here come from the three waves of assessment: the outset of the research program (T1,65.8\% non-referred children); the 12-month follow-up (T2, 59.3\% non-referred children); and the 24-month follow-up (T3, 66.1\% non-referred children). The mean age of the children was 54.69 months $(S D=11.35)$ at the time of recruitment, $64.26(S D=11.86)$ at T2 and $77.28(S D=12.30)$ at T3.

As is customary in longitudinal research, attrition occurred. Some $34 \%$ of children's attachment representations were missing at T2, and only $23 \%$ at T3. This decrease in the attrition rate between $\mathrm{T} 2$ and $\mathrm{T} 3$ could be explained by the perseverance of the research assistants, who did their best to convince the parents to participate in the last

Table 1

Socio-demographic characteristics of the two subsamples.

\begin{tabular}{|c|c|c|}
\hline Socio-demographic characteristics & $\begin{array}{c}\text { Non-referred } \\
n=245\end{array}$ & $\begin{array}{l}\text { Referred } \\
n=112\end{array}$ \\
\hline Age range in years at $\mathrm{T} 1$ (mean-standard deviation) & $4.36(1.02)$ & $3.89(.95)$ \\
\hline Gender (\% girls) & $52 \%$ & $22 \%$ \\
\hline Mothers' educational level (secondary/undergraduate + graduate) & $19 \% / 81 \%$ & $23 \% / 77 \%$ \\
\hline Fathers' educational level (secondary/undergraduate + graduate) & $29 \% / 71 \%$ & $30 \% / 70 \%$ \\
\hline Marital status (\% living together) & $89 \%$ & $82 \%$ \\
\hline Mothers' employment (\%workers) & $85 \%$ & $87 \%$ \\
\hline Fathers' employment (\%workers) & $91 \%$ & $87 \%$ \\
\hline
\end{tabular}


wave of assessment. Analysis of attrition by comparing children who dropped out and children who fully completed the three waves of data collection revealed no systematic significant differences either in the socio-demographic variables, i.e., child's age and gender, and parents' educational level, marital and employment status, or in EB, parenting, quality of attachment or cognitive abilities.

The living situation of almost all (96\%) of the children included both biological parents, and most of the children lived in two-parent families (87\%). However $13 \%$ were separated or divorced at the outset of the study; in families where parents were separated, both the mother and the father were involved in childrearing. Of the families who took part in the study, $20 \%$ had only one child, $46 \%$ had two children, and $34 \%$ had three or more children when the study began.

The educational level of the parents was taken as the number of years of education they had completed. Some $27 \%$ of mothers had completed 12 or fewer years (corresponding to the end of secondary school in Belgium); $56 \%$ had completed three more years (corresponding to undergraduate study); whereas $17 \%$ had completed a four-year degree or more. The comparable figures for fathers were $37 \%, 42 \%$ and $21 \%$.

At T1, T2 and T3, the parents were asked to complete three questionnaires, mothers and fathers separately, assessing their parenting of the target child and the child's EB. At T1, T2 and T3, each child had to complete the Fr-ASCT, and at T1 the Block Design and Information subtests of the Weschler Preschool and Primary Scale of Intelligence (WPPSI-III). At T1, the language abilities of the referred children were assessed.

\section{Measures of time-varying variables}

Attachment representations were assessed by Les Histoires à completer, the French version of the Attachment Story Completion Task (ASCT; Bretherton et al., 1990). ASCT and its adaptations have been cross-validated in several studies with children's responses to actual separation/reunion episodes (such as the Strange Situation Procedure; e.g. Gloger-Tippelt et al., 2002; Solomon et al., 1995). The results seem to support the assumption that story completions reflect the child's attachment representations of himself/herself and of his/her parents. The procedure we used included five story stems: (a) the child figure causes an accidental mishap (spills juice at the dinner table), (b) is hurt (falls off a rock in a park), (c) is afraid (of a monster in the bedroom), and experiences (d) a separation from, and (e) a reunion with, his or her parents (the parents leave for a trip while the grandmother looks after the children). In addition, an initial story stem (a birthday party) served as a warm-up procedure to familiarize the child with the procedure. The administration of the task was video-recorded.

Among the different existing coding systems for the ASCT, the children's narratives were coded by the clinical research assistants using the French Q-set procedure, Cartes pour le Codage des Histoires à completer (CCH; Miljkovitch et al., 2003), which was developed by Pierrehumbert (in English, Miljkovitch et al., 2004). The items are presented on cards. The first step of the $\mathrm{CCH}$ coding procedure consists of sorting the cards into seven piles (free distribution), from the most to the least characteristic of the child's narrative. The second step consists of a forced distribution, in which only a specific number of cards are kept in each pile. Each item receives a score (range 1-7). Four Qcorrelations are computed with the scores of the forced distribution, by comparing the children's individual Q-set description with the criterion sort provided by experts for a prototypical child using Main and Cassidy's four patterns (secure, avoidant, ambivalent and disorganized; Miljkovitch et al., 2003). These Q-correlations are continuous scores varying from +1.00 to -1.00 , with a higher score indicating greater security, avoidance, ambivalence or disorganization. In the current study, only the security (across age, mean $=.35, S D=.27$, range from -.63 to .88 ) and disorganization (across age, mean $=-.42, S D=.21$, range from -.73 to .72) Q-scores were used for analysis.

At each wave of assessment, $20 \%$ of video-recorded ASCTs, for both the referred and the non-referred groups, were coded separately by five independent coders, with a total of 16 judges. Each coder was coached by the author of this paper. The agreement was measured between each of these coders and the trainer. For the present paper, the agreement between all these coders for the two attachment Q-scores was computed using intra-class correlations (ICCs) at T1, T2 and T3. These coefficients illustrate the advantage of taking into account differences in scoring means for each coder (Howell, 1998, pp. 550-553). The ICCs for the security and disorganization Q-scores were .72 and .75 at T1, .88 and .79 at T2, and .73 and .93 at T3. These values were considered as good, although higher ICCs between coders have previously been reported using the same procedure (.94 and .90 respectively; Miljkovitch et al., 2004; Miljkovitch et al., 2007). However, the ICC mean of our values (security: .77, disorganization: .82) were similar to those that were reported for a Spanish sample of 30 randomly selected cases, with a total of 10 judges (Pierrehumbert et al., 2009). Their ICCs for the two Q-scores were .81 and .81, very similar to our results.

Parenting was assessed at T1, T2 and T3 using the Evaluation des pratiques éducatives parentales (EPEP, Meunier \& Roskam, 2007). This is based on previous studies by Van Leeuwen and Vermulst (2004) and contains 35 items relating to nine factors: Positive Parenting, Monitoring, Rules, Discipline, Inconsistent Discipline, Harsh Punishment, Ignoring, Material Rewarding, and Autonomy. Validated on 493 French-speaking mothers and fathers of normally developing children, the EPEP scale has good psychometric properties. Cronbach's alpha ranged from .65 to .89; the total percentage of variance explained by the nine factors was $64.3 \%$; test/retest correlations for a sample of 45 parents varied between .51 and .84 . Confirmatory factor analyses from the validation study showed that two second-order factors covering the supportive and controlling dimensions of parenting emerged from the initial factor solution. The supportive factor was composed of Positive Parenting, Autonomy, and Rules and included items such as "When my child seems to have a problem, I discuss with him/her what is wrong". The controlling factor included Discipline, Harsh Punishment, and Ignoring and included items such as "When my child does something that is not allowed, I only talk to him/her again when he/she behaves better". These two dimensions are highly independent at each wave of assessment, T1: mothers: $r(202)=-.15, p<.10 /$ fathers: $r(202)=-.01, p>.10$; T2: mothers: $r(202)=-.08, p>.10 /$ fathers: $r(202)=-.09, p>.10$; T3: mothers: $r(202)=-.00, p>.10 /$ fathers: $r(202)=-.02, p>.10$. These two factors had good ecological validity in comparison with a semi-structured interview assessing parenting (Roskam, Meunier, Mouton, \& Vassart, 2009). Moderately significant correlations ( $n=49$ ) were observed between the two assessments, ranging from .51 (rewarding, $p<.01$ ) to .84 (discipline, $p<.01$ ). As in Meunier et al. (2011), in order to limit the number of predictors in the models, a support-to-negative-control ratio was calculated by dividing the support score by the negative control score. A score of 1 thus indicated equal amounts of support and negative control, whereas a score less than 1 indicated more negative control than support, and a score greater than 1 indicated more support than control. In the current study, scores averaging the mother's and the father's ratios were used because there were significant correlations between the two parents' scores, T1: $r(355)=.40, p<.01 ; \mathrm{T} 2: r(335)=.34$, $p<.01$; T3: $r(343)=.39, p<.01$.

Child EB was assessed at T1, T2 and T3 separately by the two parents, who were asked to complete the four subscales (angry, aggressive, egotistical and oppositional behavior) of the Profil Socio-Affectif (PSA; Dumas, LaFrenière, Capuano, \& Durning, 1997). The PSA is the French version of the Social Competence and Behavior Evaluation: Preschool Edition (SCBE; LaFreniere \& Dumas, 1995), formerly known as the Preschool Socio-Affective Profile (LaFreniere, Dumas, Capuano, \& Dubeau, 1992). This instrument has a developmental background, emphasizing the functional meaning of affect in regulating social interactions. It provides 6-point Likert-type scales for each item, ranging from almost never occurs to almost always occurs and was designed to assess patterns of social competence, emotional regulation and 
expression, and adjustment in children aged from 30 to 78 months (LaFreniere et al., 1992). In the original validation study (LaFreniere et al., 1992), EB factors emerged in four clusters: Angry, Aggressive, Egotistical, Oppositional. Subsequent studies confirmed the construct validity of the PSA across different cultures and different samples (LaFreniere \& Dumas, 1995). The French adaptation of the scale was validated on a sample of 800 preschoolers ( 387 girls, 413 boys), and demonstrated good properties with high internal consistency, a large amount of variance explained by the factors, high inter-judge agreement and good test/retest correlations, and no correlation with social desirability. Cronbach's alpha was .86 at T1 and .89 at T3, ensuring good validity of the measure in the longitudinal collection of data. The scoring of the PSA is such that a higher score on the scale corresponds to a higher level of behavioral adjustment, in other words to a lower level of EB. For the readability of the results, we directly report and interpret the PSA scores in terms of EB (see the results and discussion section below). In the present study, the mean of the mother's and father's assessment of their child's behavior was computed for each wave of assessment because significant moderate correlations occurred between their assessments.

\section{Measure of time-invariant variable}

A brief evaluation of IQ was carried out using two subtests of the WPPSI-III (Wechsler, 2004): the block design subtest (for reasoning IQ) and the information subtest (for verbal IQ). These subtests have been found to correlate highly with the full-scale IQ (Anastasi \& Urbina, 1997), and this was confirmed in referred children completing all the WPPSI-III, reasoning IQ: $r(112)=.74, p<.01$; verbal IQ: $r(112)$ $=.77, p<.01 \mathrm{IQ}$ is treated as a time-invariant variable, because it has been shown to be relatively stable across time (e.g. Grégoire, 2006; Neyens \& Aldenkamp, 1997). For instance, Neyens and Aldenkamp (1997) reported significant test/retest correlations (over six-month intervals) for verbal, $r(21)=.69$, reasoning, $r(21)=.79$, and fullscale, $r(21)=.84$, IQ as given by the WPPSI-III. Data were only available over two-year intervals (at T1 and T3), which is why this variable could not be considered as a time-variant predictor. However, our results indicated significant stability, reasoning IQ: $r(399)=.48, p<.01$; verbal IQ: $r(399)=.37, p<.01)$. Consequently, means of reasoning IQ and verbal IQ were used in the current study: they were $9.84(S D=2.85$, range from 1 to 19 ) and 9.59 ( $S D=2.87$, range from 1 to 18 ) respectively.

\section{Measure of language abilities}

At $\mathrm{T} 1$, the language abilities evaluation included articulation and phonology, lexicon in comprehension and production, and morphosyntax in comprehension and production. Articulation and phonology, and lexicon in comprehension and production, were evaluated through a French battery, the NEEL (Chevrie-Muller \& Plaza, 2001). In the evaluation of articulation and phonology, children were asked to name different pictures. The task consisted of three lists evaluating different types of target words. For each list, a score was given for naming and for repetition, repetition being used to evaluate the stability of errors. Lexical skills in comprehension and production were assessed using the vocabulary subtests of the NEEL. To assess comprehension, children had to point (on a sheet of paper) to the word pronounced by the examiner. To assess production, children had to name a set of single pictures. French tests were used to assess morphosyntactic skills in comprehension (Evaluation du Langage Oral, ELO; Khomsi, 2001) and production (Test de Closure Grammaticale, TCG; Deltour, 1992). In the ELO, the child was shown four pictures and had to point to the one that corresponded to a sentence spoken by the examiner. In the TCG, the child was given sheets which each contained two pictures. The examiner began a sentence describing the first picture and the child had to finish the sentence with reference to the second picture (e.g., here the boy is seated, and there he... -runs-). To provide a comprehensive view of these data, multiple factor analysis (MFA; Escofier \& Pages, 1998) was run on the raw scores at each wave of assessment, to give a weighted principal component analysis. This procedure led to a single loading factor for each child, explaining $60 \%$ of the variance. In the current sample, the mean of language abilities is $-.02(s d=1.88$, range from -7.14 to 2.31 ).

\section{Results}

\section{Analysis strategies}

Prior to examining the developmental course of attachment dimensions, several preliminary analyses were conducted. Pearson correlation coefficients were calculated to examine the relations between security Q-score, disorganization Q-score, parenting and child's EB.

The main analyses performed on the continuous scores were those intended to examine the developmental course of the attachment dimensions (security and disorganization Q-scores). These were conducted using a multilevel modeling (MLM) framework with the HLM 6.06 software (Raudenbush, Bryk, Cheong, \& Congdon, 2008). The MLM framework provides a flexible method of modeling change, providing information about the variability of individuals over time as well as that between individuals.

MLM has several advantages over other methods of modeling. First, attrition is common in longitudinal data, and MLM estimates are based on all the available data, with the assumption that the missing data are random (Raudenbush, Brennan, \& Barnett, 1995). In our study, there were no systematic differences between the children who stayed in the study and those who dropped out on either the sociodemographic variables or the variables under investigation. So the missing data presented little threat to the validity of the study, and it is reasonable to consider them as random. Second, MLM allows both time-varying and time-invariant predictors to be included in models (Raudenbush et al., 1995), so the changes in attachment dimensions can be predicted from time-varying predictors (parenting and children's EB) as well as from time-invariant predictors (gender, language abilities and IQ).

The time-varying predictors are those that are measured on each occasion and are expected to vary across occasions. In the current study, parenting and children's EB were treated as time-varying predictors because they were expected to vary over time. In longitudinal models, time-varying predictors are composed of two sources of variations (within- and between-person variations), which represent two different theoretical constructs. Within-person variations are seen as acute factors giving reasons why parenting and/or child's EB is better or worse on some measurement occasion than on others. In addition to these within-person variations that are entered at Level 1 in the model, time-varying predictors also contain systematic betweenperson variations that have to be considered at Level 2 of the model. The between-person variations in time-invariant predictors represent chronic factors that can result in the parenting of a given child being more or less supportive, such as lifestyle differences or personal variables. The within- and between-person variations in time-varying predictors differ from each other. Their effects on attachment dimensions have to be differentiated in the model, because they could be of different magnitudes or even different directions (Hoffman \& Stawski, 2009). According to Hoffman and Stawski (2009, p. 119), "failure to explicitly consider separate between- and within-person sources of variation when modeling repeated measures data can lead to biased results and potentially incorrect conclusions about within-person relationships over time". Time-invariant predictors are those measured only once per person because they are not likely to change over the course of the study (Hoffman \& Stawski, 2009).

Several models for predicting the developmental trajectories of the attachment dimensions were tested. All the analyses were conducted 
separately for the security and disorganization Q-scores. As is customary, unconditional means models were run to calculate the intraclass correlation coefficient (ICC). The ICC - estimated by dividing the Level 2 variance by the total variance in a model with no predictors - allowed us to evaluate the relative magnitude of the within-person (Level 1) and the between-person (Level 2) variance components of both attachment dimensions. The ICC is also a measure of the average autocorrelation of the dependent variable over time (Singer \& Willett, 2003), giving an index of the average stability of attachment dimensions. The unconditional growth models - in which time is the only predictor - were tested to examine the developmental trajectories of attachment dimensions, before models which included predictors of change.

For our purposes, the time component was the child's age, in years, at each of the three assessment waves. The time unit in the MLM estimates was therefore one year. This time component enabled us to compute an accelerated design from three to eight years of age.

The aim of an accelerated design is to estimate mean change and its predictors over a broad range of ages by using data collected over a relatively short period of time (Miyazaki \& Raudenbush, 2000).

Unconditional models can determine whether there is significant variability between individuals in the slope coefficient which is of interest here. If significant variability is detected, then it is justifiable to include other variables in the model to predict the differences in individuals' slopes.

The first conditional model tested the predictive power of individual predictors on the developmental course of the attachment dimensions. Children's EB was entered as a time-varying predictor ( mean $=65.35$, $S D=13.24$, range from 19.50 to 95.50 ). The model examined whether the average level of children's EB, and changes in that level, predicted the developmental course of the attachment dimensions. At Level 1, the time-varying predictor was group-mean (or within-person) centered, and was constrained to have fixed effects. Group meancentering is an important technique for addressing bias in timevarying covariates due to unobserved heterogeneity or unmeasured factors that vary across individuals and have a consistent effect over time on the construct of interest (Coley, Votruba-Drzal, \& Schindler, 2008). If there was significant variability in the slope, the average level of the child's EB over the three time periods was calculated, and added as a predictor of the slope coefficient at Level 2 (mean $=64.38$, $S D=12.50$, range from 20.00 to 89.69), along with the other timeinvariant predictors such as gender, verbal and reasoning IQ (see Raudenbush et al., 1995). The aim of this procedure was to examine the pure effect of change in the time-varying predictor over time, as its mean level was controlled for (Hoffman \& Stawski, 2009). To ensure that the effects were not related to language abilities rather than to attachment representations, language abilities were entered in the Level 2 equation.

The second conditional model tested the predictive power of the caregiving environmental predictors. The time-varying predictor (parenting) was added in the Level 1 equation (mean $=1.67$, $S D=0.39$, range from 0.81 to 4.31 ). The model examined whether the average level of parenting, and changes in that level, predicted the developmental course of the attachment dimensions. If there was significant variability in the slope, the average level of parenting over the three time periods was calculated, and added as a predictor of the slope coefficient at Level 2 (mean $=1.65, S D=0.33$, range from 0.88 to 2.85 ) as language abilities, for a subsample of children, in order to control its effects.

\section{Preliminary analyses}

The correlation coefficients used to assess the stability over time of each of the constructs which were measured more than once (security Q-score, disorganization Q-score, parenting and children's EB) are presented in Table 2 . The results show moderate stability in security Qscores (with correlation coefficients ranging from .32 to .34), low stability in disorganization Q-scores (correlations ranging from .17 to .22) and fairly high stability in parenting (correlations ranging from .60 to .66 ) as well as in children's EB (correlations ranging from .77 to .78).

\section{Results of the unconditional models}

The unconditional means models were run only to calculate the intra-class correlation coefficients (ICCs), and are therefore not presented in the table. For the security Q-score the ICC was 38\%, and for the disorganization Q-score, 26\%. This suggests that the variance of both attachment dimensions is more due to variations within children $(62 \%$ and $74 \%$ respectively) than to differences between children.

Two unconditional models, one for security and one for disorganization Q-scores, were tested to examine the developmental trajectories of the attachment dimensions. The results of the fixed effects of the model indicate that the slope was significantly different from zero (Table 3). Positive slope values show that the security Q-score increased by .053 and the disorganization Q-score decreased by .023 points per year. This indicates a significant linear improvement in both security and disorganization with age.

The results from the random part of the model indicate that there was significant individual variation around the slopes of security and disorganization Q-scores and that it was therefore appropriate to examine the predictors of the rates of linear change in the attachment dimensions. Predictors at Level 2 were therefore explored.

\section{Results of the conditional models}

The first conditional model examined whether the children's EB (as a time-varying predictor) and individuals' time-invariant characteristics (gender, EB, reasoning IQ and verbal IQ) predicted the developmental course of their attachment Q-scores. The results of the fixed-effect random-effect coefficients of individual predictors on the trajectories of security and disorganization Q-scores are shown in Table 4. Gender and EB were significantly related to the developmental trajectory of the security Q-score $(\gamma=-.008, p<.01 ; \gamma=.001, p<.05)$ as well as to the developmental trajectory of disorganization Q-score $(\gamma=.006$, $p<.01 ; \gamma=-.001, p<.01)$.

Table 2

Pearson correlation coefficients examining the stability of the time-varying variables.

\begin{tabular}{|c|c|c|c|c|c|c|c|c|}
\hline & \multicolumn{2}{|c|}{ Security Q-score } & \multicolumn{2}{|c|}{ Disorganization Q-score } & \multicolumn{2}{|c|}{ Parenting } & \multicolumn{2}{|c|}{ Children's EB } \\
\hline & $\mathrm{T} 2$ & T3 & $\mathrm{T} 2$ & T3 & $\mathrm{T} 2$ & T3 & $\mathrm{T} 2$ & T3 \\
\hline $\mathrm{T} 1$ & $.32^{* *}$ & $.32^{* *}$ & $.18^{* *}$ & $.17^{* *}$ & $.66^{* *}$ & $.60^{* *}$ & $.78^{* *}$ & $.77^{* *}$ \\
\hline$n$ & 258 & 311 & 258 & $311^{*}$ & 222 & 203 & 198 & 196 \\
\hline $\mathrm{T} 2$ & & $.34^{* *}$ & & $.22^{* *}$ & & $.66^{* *}$ & & $.70^{* *}$ \\
\hline$n$ & & 252 & & 252 & & 161 & & 138 \\
\hline
\end{tabular}

* $p<0.05, * * p<0.01$. 
Table 3

Results of MLM unconditional growth models: estimates of the intercepts, linear change, and variance in attachment dimensions.

\begin{tabular}{|c|c|c|c|c|}
\hline & \multicolumn{3}{|c|}{ Fixed effects } & \multirow{2}{*}{$\begin{array}{c}\text { Random effects } \\
\text { variance }\end{array}$} \\
\hline & Coefficient & SE & t-ratio $(d f)$ & \\
\hline \multicolumn{5}{|c|}{ Security Q-score } \\
\hline Intercept & .082 & .046 & $1.806(607)^{(*)}$ & $.01^{*}$ \\
\hline Slope & .053 & .009 & $6.109(273)^{* * *}$ & $.06^{* * *}$ \\
\hline Deviance & 119.18 & & & \\
\hline \multicolumn{5}{|c|}{ Disorganization Q-score } \\
\hline Intercept & -.307 & .034 & $-8.873(607)^{* * *}$ & $.01^{* *}$ \\
\hline Slope & -.023 & .006 & $-3.502(273)^{* * *}$ & $.03^{* * *}$ \\
\hline Deviance & -150.42 & & & \\
\hline
\end{tabular}

${ }^{(*)} p<.10,{ }^{*} p<.05,{ }^{* *} p<.01,{ }^{* * *} p<.001$.

Once language abilities being controlled for in the conditional model for the referred children only, a significant effect of reasoning IQ $(\gamma=.003, p<.10)$ tended to appear over and above the influence of language abilities on the completion of the Fr-ASCT $(\gamma=.009$, $p<.01)$. Having a high level of language ability and high reasoning IQ had a positive impact on the developmental course of the security Qscore.

Only the significant influence of children's EB $(\gamma=-.000$, $p<.01$ ) on the developmental course of the disorganization Q-score remained when the influence of language ability was controlled for $(\gamma=-.003, p>.10)$. Children with low EB had a more positive developmental course with respect to disorganization than their opposites.

The second conditional model examined whether the average level of parenting and changes in that level predicted the developmental course of attachment Q-scores. The results of the fixed-effect randomeffect coefficients of the caregiving environmental predictors on security and disorganization Q-scores are presented in Table 4. The average level of parenting positively influenced the developmental course of the security $(\gamma=.023, p<.01)$ and disorganization Q-score $(\gamma=-.015, p<.05)$, meaning that variations in parenting across measurement occasions were associated with improvement in the two attachment Q-scores.

As for the first conditional model, language abilities were controlled for in the conditional model for a subsample of children. Language abilities had a substantial effect on the increase of the security Q-score $(\gamma=.006, p<.01)$. Consequently, the effect of parenting disappeared when language abilities were controlled for. However, for the disorganization Q-score, the results show that the significant effect of the average level of parenting remained $(\gamma=-.017, p<.10)$.

\section{Discussion}

The main purpose of the current research was to examine the stability of attachment representations within childhood, and the possible effects of several children's and caregiver's characteristics on the development of these representations. Several direct effects of the caregiving environment and the child's characteristics were tested. Only some of our hypotheses were supported by the results.

Using an accelerated design, security and disorganization Q-scores were not stable, but developed between the ages of three and eight. Unconditional models where time was the only predictor indicated positive and significant values for the slope of these variables. On average, children became more secure and less disorganized as they got older. Hence attachment stability was not as clear cut as it looked at first. This suggests that, as suggested by the life-span developmental perspective (e.g., Weinert \& Weinert, 1999), each child is able to develop his or her own attachment representations across his/her development, depending on personal characteristics and differential susceptibility to the environment.

The role played by some children's and caregiver's characteristics influencing the attachment stability in the developmental trajectories of attachment representations has only infrequently been explored in the past, but this study has shown it to be important.

Previous studies (Bretherton, 2008; Gloger-Tippelt et al., 2008; Miljkovitch et al., 2007) have suggested that language was unimportant because the use of material aids allows the child to tell his or her story without speaking. However, our results suggest that language abilities play a role in the developmental course of mainly the security Q-score, confirming our clinical sense that it was difficult to carry out the story

Results of conditional MLM of child and contextual variables predicting changes in Security and Organization.

\begin{tabular}{|c|c|c|c|c|}
\hline \multirow[b]{3}{*}{ Fixed effects } & \multicolumn{2}{|c|}{ Security Q-score } & \multicolumn{2}{|c|}{ Disorganization Q-score } \\
\hline & $\begin{array}{c}\text { All } \\
(n=358)\end{array}$ & $\begin{array}{c}\text { Referred } \\
(n=113)\end{array}$ & $\begin{array}{c}\text { All } \\
(n=358)\end{array}$ & $\begin{array}{c}\text { Referred } \\
(n=113)\end{array}$ \\
\hline & Coefficient (SE) & Coefficient (SE) & Coefficient (SE) & Coefficient (SE) \\
\hline \multicolumn{5}{|c|}{ First conditional model (child variables) } \\
\hline \multicolumn{5}{|c|}{ Level 1 time-varying covariates } \\
\hline EB & $.000(.001)$ & $-.001(.002)$ & $.000(.001)$ & $-.001(.002)$ \\
\hline \multicolumn{5}{|l|}{ Level 2} \\
\hline Intercept & $.048(.008)^{* * *}$ & $.032(.018)^{*}$ & $-.017(.007)^{*}$ & $.035(.014)^{*}$ \\
\hline Gender & $-.008(.002)^{* * *}$ & $-.009(.005)$ & $.006(.002)^{* *}$ & $.004(.004)$ \\
\hline Reasoning IQ & $.001(.001)$ & $.003(.002)^{(*)}$ & $.000(.000)$ & $-.000(.001)$ \\
\hline Verbal IQ & $.001(.001)$ & $-.001(.001)$ & $.000(.000)$ & $-.000(.001)$ \\
\hline $\mathrm{EB}$ & $.001(.001)^{*}$ & $.001(.000)$ & $-.001(.000)^{* * *}$ & $-.000(.001)^{*}$ \\
\hline Language & - & $.009(.002)^{* * *}$ & - & $-.002(.002)$ \\
\hline Deviance & 159.06 & 92.89 & 119.37 & 14.89 \\
\hline \multicolumn{5}{|c|}{ Second conditional model (contextual variables) } \\
\hline \multicolumn{5}{|c|}{ Level 1 time-varying covariates } \\
\hline Parenting & $.034(.053)$ & $.040(.082)$ & $-.035(.045)$ & $-.046(.089)$ \\
\hline \multicolumn{5}{|l|}{ Level 2} \\
\hline Intercept & $.048(.009)^{* * *}$ & $.029(.014)^{*}$ & $-.019(.007)$ & $.030(.012)^{*}$ \\
\hline Mean parenting & $.023(.007)^{* *}$ & $.016(.011)$ & $-.015(.006)^{*}$ & $-.017(.009)^{(*)}$ \\
\hline Language & - & $.007(.002)^{* *}$ & - & $.003(.001)$ \\
\hline Deviance & 122.10 & 70.18 & 144.46 & 54.49 \\
\hline
\end{tabular}

${ }^{(*)} p<.10,{ }^{*} p<.05,{ }^{* *} p<.01,{ }^{* * *} p<.001$. 
completions, and then the Q-set procedure, when the child did not speak or spoke very little. This may have resulted in incorrect estimates of the attachment patterns. Consequently, the role of language abilities in the story completion task was controlled for in the analysis of the referred children. Our results showed that some children's and caregiver's characteristics had an impact on the development course of the attachment dimensions, over and above the effect of language abilities. So, even if language abilities influenced the completion of the stories, and consequently the scoring of the Fr-ASCT, the Q-scores can be considered as a reliable measure of children's attachment representations irrespective of language abilities, as also mentioned by Stievenart et al. (2012). Nevertheless, further study of the relations between language abilities and attachment representations might well be fruitful.

Furthermore, when language abilities were controlled for, the gender effect disappeared, suggesting that further analyses are needed to confirm that this gender-related effect could be due to the sort of the task, i.e. production narrative. A meta-analysis of gender differences in verbal ability found a mean effect size (favoring girls) of .11 (Hyde \& Linn, 1988). This could explain why a gender effect is observed in the attachment Q-scores, but disappeared when language abilities were controlled for. Further studies are needed to confirm that this genderrelated effect is indeed due to language abilities (i.e., narrative production). Mean comparisons of language abilities need to be run between boys and girls, with the expectation that girls will display stronger language abilities than boys. If this is true, gender-related effects on children's narratives could be explained by this difference. This would lead to the recommendation that the gender should be controlled for in any further analyses employing data from the Fr-ASCT.

Some of the effects of the children's and caregiver's characteristics influencing the attachment stability were different for security and disorganization Q-scores. This indicates the importance of considering security and disorganization as two independent dimensions, as was recently suggested by Stievenart et al. (2011) as well as the relevance of a recent "shift of emphasis away from the importance of the distinction between secure/insecure to that between organization/disorganization" (Green \& Goldwyn, 2002, p. 840). Further empirical results should therefore keep on with this distinction between security and organization of children's attachment representations in order to highlight their conceptual properties.

For the security Q-score, when language abilities were controlled for, an effect of reasoning IQ appeared. This confirmed that cognitive abilities, over and above language abilities, have an impact on the development of attachment representations. In this research, reasoning IQ was measured by the block design subtest, which involves the capacity to analyze and synthesize abstract visual stimuli as well as to create non-verbal concepts (Wechsler, 2004). It may be that such cognitive abilities are an important step in the development of attachment representations. The capacities acquired to synthesize and create non-verbal concepts can be very helpful for the two main functions of attachment representations, i.e. the interpretation and the prediction of external events and the behavior of others (Crittenden, 1990). A child displaying good reasoning abilities would therefore be more likely to create and refer to secure attachment representations earlier in his or her development. Conversely, a child displaying lower reasoning abilities needs more time to create and refer to secure attachment representations.

A different pattern of results emerged for children's and caregiver's characteristics influencing the disorganization Q-score growth curve. Its developmental course was mainly influenced by the child's EB. Such a result was congruent with previous results suggesting that disorganization is a major risk factor for developmental disorders (e.g. Fearon et al., 2010; Green \& Goldwyn, 2002). These results lead to some important considerations for clinical purposes as well as giving empirical support to existing parenting programs. Because relations were well established between parenting and children's EB (e.g., Meunier et al., 2011), the impact of EB on the development of the disorganization Q-score has highlighted the importance of childrearing behavior that can be improved by parenting programs. Such programs promote parental development through the implementation of positive support, rules, autonomy demands and monitoring techniques, and a decrease in inconsistent parenting, harsh punishment, ignoring and material rewarding techniques (e.g., Juffer, Bakermans-Kranenburg, \& van Ijzendoorn, 2008). These negative strategies are progressively replaced by more supportive ones. Good parental development is expected to decrease children's EB and consequently improve the development of organized attachment representations. These parenting programs are of particular interest for parents rearing a child displaying EB because of the difficulty of being a supportive parent when faced with a child who behaves disruptively (Roskam \& Meunier, 2012; Verhoeven, Junger, van Aken, Deković, \& van Aken, 2010).

Although innovative and important from both clinical and research perspectives, the present study is by no means definitive. First of all, our results concerning the effect of language abilities were obtained from the referred sample, and therefore need to be replicated in normally-developing children. Attempts should also be made to replicate the findings in other developmental periods, using other referred and culturally diverse groups of children, to capture the specificities of the development of attachment representations in various clinical samples and in culturally diverse environments.

\section{References}

Ainsworth, M. S., Blehar, M. C., Waters, E., \& Wall, S. (1978). Patterns of attachment: A psychological study of the strange situation. Oxford, England: Lawrence Erlbaum.

Anastasi, A., \& Urbina, S. (1997). Psychological testing (7th ed.). Englewood Cliffs, US NJ: Prentice-Hall.

Bar-Haim, Y., Sutton, D. B., \& Fox, N. A. (2000). Stability and change of attachment at 14, 24 and 58 months of age: Behavior, representation, and life events. Journal of Child Psychology and Psychiatric, 41(3), 381-388. http://dx.doi.org/10.1111/1469-7610.00622.

Bretherton, I. (2008). Les histoires à compléter pour l'étude des représentations d'attachement. Enfance, 60(1), 13-21. http://dx.doi.org/10.3917/enf.601.0013.

Bretherton, I., Ridgeway, D., \& Cassidy, J. (1990). Assessing internal working models of the attachment relationship: An attachment story completion task for 3-year-olds. Attachment in the preschool years: Theory, research, and intervention (pp. 273-308). Chicago, IL: University of Chicago Press.

Cassidy, J. (2003). Continuity and change in the measurement of infant attachment: Comment on Fraley and Spieker (2003). Developmental Psychology, 39(3), 409-412. http://dx.doi.org/10.1037/0012-1649.39.3.409.

Chevrie-Muller, C., \& Plaza, M. (2001). Nouvelles Epreuves pour l'Examen du Langage (N-EEL). Paris France: Editions du Centre de Psychologie Appliquée.

Coley, R. L., Votruba-Drzal, E., \& Schindler, H. S. (2008). Trajectories of parenting processes and adolescent substance use: Reciprocal effects. Journal of Abnormal Child Psychology: An official publication of the International Society for Research in Child and Adolescent Psychopathology, 36(4), 613-625. http://dx.doi.org/10.1007/s10802-007-9205-5.

Crittenden, P. (1990). Internal representational models of attachment relationships. Infant Mental Health Journal, 11(3), 259-277. http://dx.doi.org/10.1002/1097-0355(199023) 11:3<259:AID-IMHJ2280110308>3.0.CO;2-J.

Cummings, E. M. (2003). Toward assessing attachment on an emotional security continuum: Comment on Fraley and Spieker (2003). Developmental Psychology, 39(3), 405-408. http://dx.doi.org/10.1037/0012-1649.39.3.405.

Cummings, E. M., Greenberg, M. T., \& Cicchetti, D. (1990). Classification of attachment on a continuum of felt security: Illustrations from the study of children of depressed parents. Attachment in the preschool years: Theory, research, and intervention (pp. 311-338). Chicago, IL: University of Chicago Press.

De Wolff, M., \& van Ijzendoorn, M. (1997). Sensitivity and attachment: A meta-analysis on parental antecedents of infant attachment. Child Development, 68(4), 571-591. http://dx.doi.org/10.2307/1132107.

Deltour, J. -J. (1992). Test de closure grammaticale pour enfants de 3 à 9 ans (TCG 3-9). Liège Belgium: Presses Universitaires de Liège.

Dumas, J., LaFrenière, P., Capuano, F., \& Durning, P. (Eds.). (1997). Profil Socio-Affectif (PSA). Évaluation des compétences sociales et des difficultés d'adaptation des enfants de 21/2 à 6 ansSocio-affective profile: Rating of social competence and adaptive behavior of 2- to 6-years-old children. Paris France: Éditions du Centre de Psychologie Appliquée.

Egeland, B., \& Farber, E. A. (1984). Infant-mother attachment: Factors related to its development and changes over time. Child Development, 55(3), 753-771. http://dx.doi.org/10.2307/1130127.

Escofier, B., \& Pages, J. (1998). Analyses factorielles simples et multiples. Objectifs, methodes et interpretation (3rd ed.). Paris France: Dunod.

Fearon, R. M. P., Bakermans-Kranenburg, M. J., van Ijzendoorn, M. H., Lapsley, A. -M., \& Roisman, G. I. (2010). The significance of insecure attachment and disorganization in the development of children's externalizing behavior: A meta-analytic study. Child Development, 81(2), 435-456. http://dx.doi.org/10.1111/j.1467-8624.2009.01405.x. 
Gloger-Tippelt, G., Gomille, B., Koenig, L., \& Vetter, J. (2002). Attachment representations in 6-year-olds: Related longitudinally to the quality of attachment in infancy and mother's representations. Attachment and Human Development, 4(3), 318-339. http://dx.doi.org/10.1080/14616730210167221.

Gloger-Tippelt, G., Lilith, K., \& Olaf, L. (2008). Représentations d'attachement évaluées avec les histoires à compléter et troubles du comportement chez des enfants de 6 ans. Enfance, 60(1), 42-50. http://dx.doi.org/10.3917/enf.601.0042.

Green, J., \& Goldwyn, R. (2002). Annotation: Attachment disorganisation and psychopathology: New findings in attachment research and their potential implications for developmental psychopathology in childhood. Journal of Child Psychology and Psychiatric, 43(7), 835-846. http://dx.doi.org/10.1111/1469-7610.00102.

Green, J., Stanley, C., \& Peters, S. (2007). Disorganized attachment representation and atypical parenting in young school age children with externalizing disorder. Attachment $\mathcal{E}$ Human Development, 9(3), 207-222. http://dx.doi.org/10.1080/14616730701453820.

Green, J., Stanley, C., Smith, V., \& Goldwyn, R. (2000). A new method of evaluating attachment representations in young school-age children: The Manchester Child Attachment Story Task. Attachment and Human Development, 2(1), 48-71.

Grégoire, J. (Ed.). (2006). L'examen clinique de l'intelligence de l'enfant. Fondements et pratique du WISC-IV. Sprimont, Belgique: Mardaga.

Hoffman, L., \& Stawski, R. S. (2009). Persons as contexts: Evaluating between-person and within-person effects in longitudinal analysis. Research in Human Development 6(2-3), 97-120. http://dx.doi.org/10.1080/15427600902911189.

Howell, D. (Ed.). (1998). Méthodes statistiques en sciences humaines. Paris France: De Boeck Université.

Huang, K. -Y., O'Brien Caughy, M., Lee, L. -C., Miller, T., \& Genevro, J. (2009). Stability of maternal discipline practices and the quality of mother-child interaction during toddlerhood. Journal of Applied Developmental Psychology, 30(4), 431-441. http://dx.doi.org/10.1016/j.appdev.2008.12.024.

Hyde, J. S., \& Linn, M. C. (1988). Gender differences in verbal ability: A meta-analysis. Psychological Bulletin, 104(1), 53-69. http://dx.doi.org/10.1037/0033-2909.104.1.53.

Juffer, F., Bakermans-Kranenburg, M. J., \& van Ijzendoorn, M. H. (2008). Promoting positive parenting: An attachment-based intervention. New York, NY: Taylor \& Francis Group/Lawrence Erlbaum Associates.

Karavasilis, L., Doyle, A.B., \& Markiewicz, D. (2003). Associations between parenting style and attachment to mother in middle childhood and adolescence. International Journal of Behavioral Development, 27(2), 153-164. http://dx.doi.org/10.1080/0165025024400015.

Khomsi, A. (2001). Evaluation du Langage Oral. Paris: Editions du Centre de Psychologie Appliquée.

LaFreniere, P., \& Dumas, J. (Eds.). (1995). Social competence and behavior evaluation (Preschool ed.). Los Angeles, CA: Western Psychological Services.

LaFreniere, P., Dumas, J., Capuano, F., \& Dubeau, D. (1992). Development and validation of the preschool socioaffective profile. Psychological Assessment, 4(4), 442-450. http://dx.doi.org/10.1037/1040-3590.4.4.442.

Main, M., \& Hesse, E. (1990). Parents' unresolved traumatic experiences are related to infant disorganized attachment status: Is frightened and/or frightening parental behavior the linking mechanism? In M. T. Greenberg, D. Cicchetti, \& E. M. Cummings (Eds.) Attachment in the preschool years: Theory, research, and intervention (pp. 161-182). Chicago, IL: University of Chicago Press.

Meunier, J. C., \& Roskam, I. (2007). Psychometric properties of a parental childrearing behavior scale for French-speaking parents, children, and adolescents. European Journa of Psychological Assessment, 23(2), 113-124.

Meunier, J. C., Roskam, I., Stievenart, M., Van de Moortele, G., Browne, D. T., \& Kumar, A (2011). Externalizing behavior trajectories: The role of parenting, sibling relationships and child personality. Journal of Applied Developmental Psychology, 32(1), 20-33. http://dx.doi.org/10.1016/j.appdev.2010.09.006.

Miljkovitch, R., \& Pierrehumbert, B. (2008). Des stratégies comportementales d'attachement aux stratégies représentationnelles: Construction et validité des cartes de codage pour les histoires à compléter. Enfance, 60(1), 22-30. http://dx.doi.org/10.3917/enf.601.0022

Miljkovitch, R., Pierrehumbert, B., Bretherton, I., \& Halfon, O. (2004). Associations between parental and child attachment representations. Attachment and Human Development, 6(3), 305-325.

Miljkovitch, R., Pierrehumbert, B., \& Halfon, O. (2007). Three-year-olds' attachment play narratives and their associations with internalizing problems. Clinical Child Psychology and Psychotherapy, 14(4), 249-257.

Miljkovitch, R., Pierrehumbert, B., Karmaniola, A., \& Halfon, O. (2003). Les représentations d'attachement du jeune enfant. Développement d'un système de codage pour les histoires à compléter. Devenir, 15(2), 143-177. http://dx.doi.org/10.3917/dev.032.0143.

Miyazaki, Y., \& Raudenbush, S. (2000). Tests for linkage of multiple cohorts in an accelerated longitudinal design. Psychological Methods, 5(1), 44-63. http: //dx.doi.org/10.1037/1082-989x.5.1.44.

Moss, E., Cyr, C., Bureau, J. -F., Tarabulsy, G., \& Dubois-Comtois, K. (2005). Stability of attachment during the preschool year. Developmental Psychology, 41(5), 773-783.

Moss, E., Smolla, N., Cyr, C., Dubois-Comtois, K., Mazzarello, T., \& Berthiaume, C. (2006) Attachment and behavior problems in middle childhood as reported by adult and child informants. Development and Psychopathology, 18(2), 425-444.
Neyens, L. G. J.. \& Aldenkamp, A. P. (1997). Stability of cognitive measures in children of average ability. Child Neuropsychology, 3(3), 161-170. http://dx.doi.org/10.1080/ 09297049708400639.

Ongari, B. (2008). Représentations d'attachement d'enfants et troubles du comportement à l'école maternelle. Enfance, 60(1), 53-62. http://dx.doi.org/10. 3917/enf.601.0053.

Pierrehumbert, B., Miljkovitch, R., Plancherel, B., Halfon, O., \& Ansermet, F. (2000). Attachment and temperament in early childhood; implications for later behavior problems. Infant and Child Development, 9, 17-32. http://dx.doi.org/10.1002/(SICI) 1522-7219(200003)9:1<17:AID-ICD212>3.0.CO;2-\#

Pierrehumbert, B., Santelices, M. P., Ibáñez, M., Alberdi, M., Ongari, B., Roskam, I., et al. (2009). Gender and attachment representations in the preschool years: Comparisons between five countries. Journal of Cross-Cultural Psychology, 40(4), 543-566. http://dx.doi.org/10.1177/0022022109335181.

Raudenbush, S., Brennan, R., \& Barnett, R. (1995). A multivariate hierarchical model for studying psychological change within married couples. Journal of Family Psychology, 9(2), 161-174. http://dx.doi.org/10.1037/0893-3200.9.2.161.

Raudenbush, S., Bryk, A., Cheong, Y., \& Congdon, R. (2008). HLM 6.06: Hierarchical linear and non-linear modeling. Lincolnwood, IL: Scientific Software International.

Roskam, I., \& Meunier, J. C. (2012). The determinants of parental childrearing behavior trajectories: The effects of parental and child time-varying and time-invariant predictors. International Journal of Behavioral Development, 36(3), 186-196. http://dx.doi.org/10.1177/0165025411434651.

Roskam, I., Meunier, J. C., Mouton, C., \& Vassart, É. (2009). Évaluer l'activité éducative parentale: Les méthodes se valent-elles? Enfance, 61(4), 423-432. http://dx.doi.org/10.4074/S0013754509004042.

Singer, J.D., \& Willett, J. B. (2003). Applied longitudinal data analysis: Modeling change and event occurrence. New York, NY: Oxford University Press.

Solomon, J., George, C., \& De Jong, A. (1995). Children classified as controlling at age six: Evidence of disorganized representational strategies and aggression at home and at school. Development and Psychopathology, 7(3), 447-463. http://dx.doi.org/10.1017/ s0954579400006623.

Stacks, A. -M. (2007). Defensive dysregulation in preschool children's attachment story narratives and its relation to attachment classification and externalizing behaviour. School Psychology International, 28(3), 294-312. http://dx.doi.org/10.1177/ 0143034307078537.

Stievenart, M., Meunier, J. C., Van de Moortele, G., \& Roskam, I. (2012). Assessment of preschoolers' attachment security using the Attachment Q-set and the Attachment Story Completion Task. The International Journal of Educational and Psychological Assessment, 12(1), 62-80.

Stievenart, M., Roskam, I., Meunier, J. C., \& Van de Moortele, G. (2011). The reciprocal relation between children's attachment representations and their cognitive ability. International Journal of Behavioral Development, 35(1), 58-66. http://dx.doi.org/10.1177/0165025410370790.

Symons, D., Clark, S., Isaksen, G., \& Marshall, J. (1998). Stability of Q-sort attachment security from age two to five. Infant Behavior \& Development, 21(4), 785-791. http://dx.doi.org/10.1016/S0163-6383(98)90045-5.

van Ijzendoorn, M., Schuengel, C., \& Bakermans-Kranenburg, M. J. (1999). Disorganized attachment in early childhood: Meta-analysis of precursors, concomitants, and sequelae. Development and Psychopathology, 11(2), 225-249. http://dx.doi.org/10.1017/ S0954579499002035.

van Ijzendoorn, M., Vereijken, C., Bakermans-Kranenburg, M. J., \& Riksen-Walraven, M. (2004). Assessing attachment security with the Attachement Q Sort: Meta-analytic evidence for the validity of the observer AQS. Child Development, 75(4), 1188-1213. http://dx.doi.org/10.1111/j.1467-8624.2004.00733.x.

Van Leeuwen, K. G., \& Vermulst, A. A. (2004). Some psychometric properties of the ghent parental behavior scale. European Journal of Psychological Assessment, 20(4), 283-298.

Verhoeven, M., Junger, M., van Aken, C., Deković, M., \& van Aken, M.A. G. (2010). Parenting and children's externalizing behavior: Bidirectionality during toddlerhood. Journal of Applied Developmental Psychology, 31(1), 93-105. http://dx.doi.org/10.1016/ j.appdev.2009.09.002.

Waters, E., \& Deane, K. (1985). Defining and assessing individual differences in attachment relationships: Q-methodology and the organization of behavior in infancy and early childhood. Monographs of the Society for Research in Child Developpment, 50(1-2), 41-65. http://dx.doi.org/10.2307/3333826.

Wechsler, D. (Ed.). (2004). WPPSI-III: Manuel d'interprétation. Paris, France: Les Editions du Centre de Psychologie Appliquée.

Weinert, F., \& Weinert, S. (1999). History and systems of developmental psychology. In A. Demetriou, W. Doise, \& C. van Lieshout (Eds.), Life-span developmental psychology. West Sussex, England: John Wiley \& Sons.

Weinfield, N. S., Whaley, G. J. L., \& Egeland, B. (2004). Continuity, discontinuity, and coherence in attachment from infancy to late adolescence: Sequelae of organization and disorganization. Attachment \& Human Development, 6(1), 73-97. http://dx.doi.org/10.1080/ 14616730310001659566. 